\title{
Primary Percutaneous Coronary Intervention (PPCI) in Acute Myocardial Infarction Complicated by Cardiogenic Shock in a Newly Emerging Cardiac Centre in Nepal
}

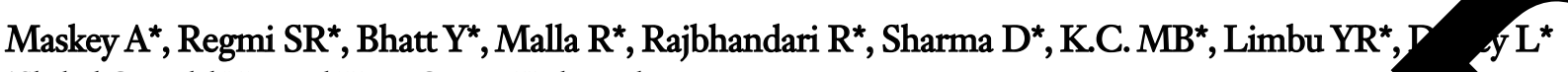 \\ *Shahid Gangalal National Heart Centre, Kathmandu.
}

Corresponding: Dr. Arun Maskey

Shahid gangalal National Heart Centre,Bansbari, Kathmandu, Nepal, Tel: 00977-1-4371322, 00977-1

Fax 00977-1-4371123, Email: maskeyarun@yahoo.com

Abstract

Background: Acute myocardial infarction (AMI) is complicat Mortality rate is exceedingly high and reaches $70-80 \%$ in those demonstrate $60 \%$ mortality with most effective thrombolytic agent. In betwed total PCI in Shahid gangalal National Heart Centre (SGP pal was 452 . a in AMI with cardilgenic shock was done in only 16 patif are in out of $50 \%(\mathrm{n}=8)$ patients with cardiogenic sh over 12 months and 2 were doing well in subsequent complicated by cardiogenic shock has lower mortality need for trained manpower are the major limitations.

diogenic shock wh derwent PPCI, 6 patients tho underwent PPCI, 6 patients are in routine follow up nths but lost ip ow up afterwards. Primary PCI in AMI Keywords : Primary Percutaned nary intervention, cardio genic shock, SGNHC (Shahid Gangalal National

\section{INTRODUCTION}

Cardiogenic shock is the com patients with acute myocardial hospital alive. Cardilgenic sho more of the left ventricle of onset of infarction $\mathrm{d} y$ . A relataively small previous damage myocardial inf in $7-10 \%$ and reacb - $0-80 \%$ in th thromb trials demonstra ogenic with AMI between Reteplase or Alteplase, pati eated with Repteplase and 58\% treated with within $30>(p=0.59)$. improved out . High cost, high in-hospital mortality,

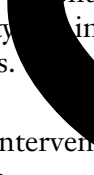

ng trend been to go for more aggressive erapeu searly in patients who have cardiogenic pck follo myocardial infarction. In the recent idelines of European Society and American College of (ACC) and the American Heart Association (AHA) Carly mechanical revascularization for cardiogenic shock for patients younger than 75 years with ST-elevation AMI or left bundle-branch block.

Invasive strategy in developing country like Nepal is not Aly costly but also technically demanding. No study has been done till date with aggressive invasive strategy in poor

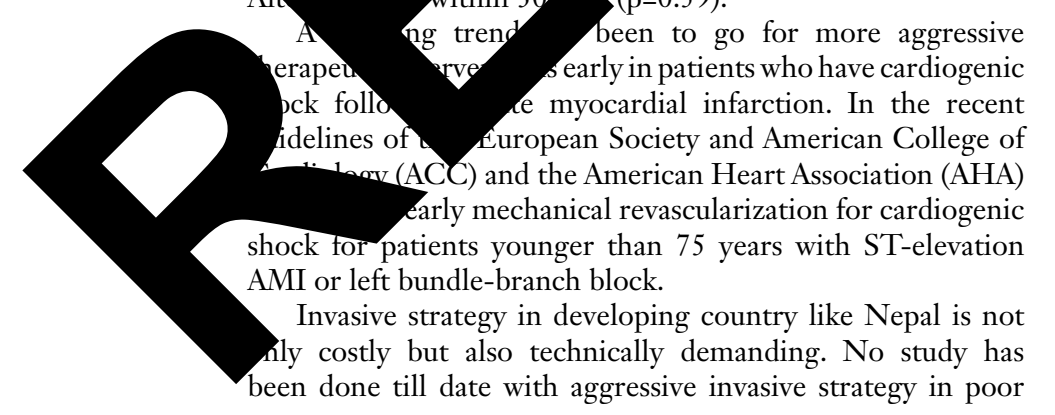

developing country like Nepal and hence its usefulness, justification and feasibility is not known. The purpose of this study was to evaluate the in-hospital mortality rate in a cohort of unselected consecutive patients with AMI complicated by cardiogenic shock treated with PPCI in SGNHC, the only national heart centre which offers this facility in Nepal.

\section{METHODS}

Sixteen consecutive patients who presented to SGNHC with ST elevation MI complicated by cardiogenic shock were studied. Those patients who presented with ST elevation MI with cardiogenic shock and mechanical complications like papillary muscle rupture, ventricular septal defect and free wall rupture in echocardiography were not considered for PPCI due to surgical indication. We do not have exact data of the whole incidence of cardiogenic shock in ST elevation MI. however, it is estimated to be approximately $5-7 \%$. Diagnosis of acute ST elevation with cardiogenic shock was defined as evidence of hypo-perfusion (cold clammy skin, cerebral obtundation), systolic blood pressure $<90 \mathrm{~mm} \mathrm{Hg}$, pulse $>100 \mathrm{bpm}$ and evidence of acute STEMI or neew onset LBBB (ischemic chest pain and ST elevation in ECG).

This is a retrospective study between September 2005 to August 2008. Total PCI in SGNHC was done in 452 patients. Among them PPCI in AMI with cardiogenic shock was done in only 16 patients $(3.5 \%)$. 


\section{RESULTS}

Clinical characteristics of the patients included in this study are shown in table 1. the interval between AMI to Cardiogenic shock PPCI was 6-30 hours. The age range was between 21-77 yrs (mean $48.5+/ 16.52$ yrs). There were 12 male and 4 female patients. The risk factors distribution showed diabetes in 4 smoking in 7 , hypertension in 4 and strong family history in 2 patients. The baseline left ventricular ejection fraction (LVEF) by echocardiography was $30-41 \%(35.57+/ 3.92)$. the culprit vessels were 7 right coronary arteries (RCA), 6 left anterior descending arteries (LAD), 2 left circumflex (LCX) and 1 left main vessel (LM). Thrombolysis in myocardial infarction (TIMI) flow among 16 patients showed pre procedure TIMI flow 0 in 14 patients ad TIMI flow 1 in 2 patients. Post procedural TIMI flow 3 was achieved in 13 patients. Intraaortic balloon pump (IABP) was used in 7 patients.

\begin{tabular}{l|l}
\multicolumn{1}{|c}{ Table 1. Patient Characteristics } \\
\hline Characteristics & \\
\hline Mean Age (years) & 48.5 \\
\hline Male Sex & 12 \\
\hline Anterior MI & 7 \\
\hline Non anterior MI & 9 \\
\hline Diabetes Mellitus & 4 \\
\hline Hypertension & 4 \\
\hline Current Smoking & 7 \\
\hline Hyperlipidemia & 3 \\
\hline IABP usage & 7 \\
\hline LVEF & 35.6 \\
\hline
\end{tabular}

$5 \pm 16.5^{n=16}$

$(75 \%)$

$(44 \%)$

$9(56 \%)$

$(25 \%)$

$4(25 \%)$

$7(44 \%)$

$3(19 \%)$

$7(44 \%)$

Among those 16 patients with complicated by cardiogenic shock patients died in-hospital and 8 sur Of 8 deaths, culprit vessel 1 died due to pre existing despite opening the culp the 8 patients who 12 months and 2 months.
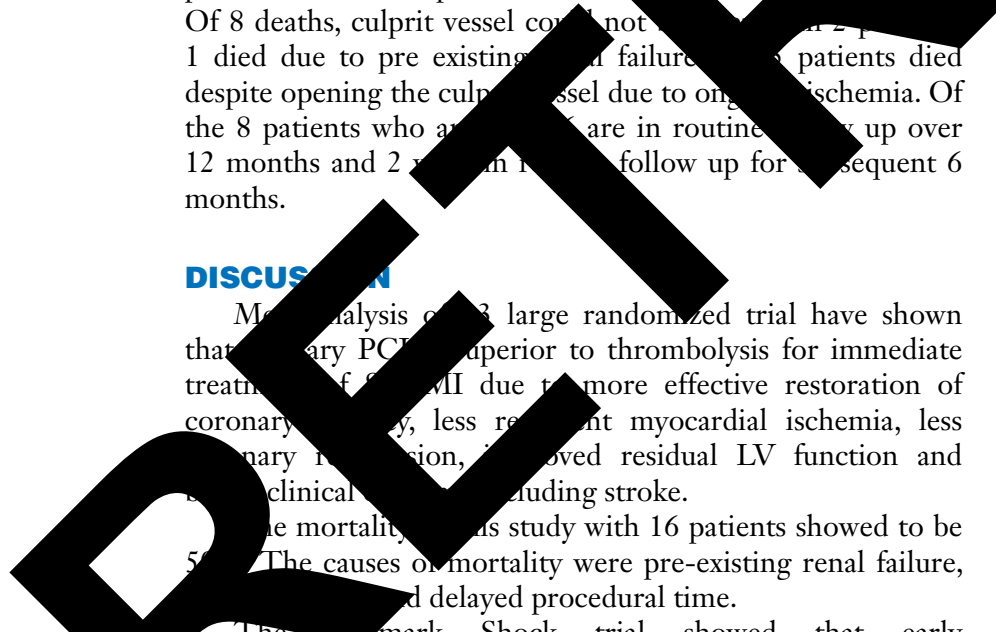
failur $5.6 \pm 3.9 \%$

5

The mark Shock trial showed that early vevascularization is better than medical management in AMI

cardiogenic shock. Thirty day survival was $54 \%$ and one irvival was $50 \%$. Thirty day survival after successful PCI wa. $65 \%$ and after unsuccessful PCI was $20 \%$. Mortality was related to TIMI flow. Mortality with TIMI grade flow showed TIMI 3 flow (mortality 98\%) TIMI 2 flow (mortality 55\%) and TIMI 1 or 0 flow (mortality 100\%). The independent predictors of mortality in shock trial was increasing age, lower systolic blood pressure, increasing age, lower systolic blood pressure, increasing time of randomization, lower post PCI TIMI flow 0/1, and multivessel PCI.

In a prospective randomized trial, 1333 patients at 80 centres in Germany between 1994 - 2001 in ALKK PCI registry $14.2 \%$ patients with AMI presented with cardig shock. The in-hospital mortality was $46.1 \%$. predicto hospital mortality was ppost procedural TIMI flo age (75 years or more) and time-interval betw onset and start of PCI.

In retrospective study between 1994 patients presenting with AMI and car hospital mortality was reported to factors for increased mortality smoking, need of mechanical predictors of impaired long triple vessel disease.

In REO - SHOC national registry 2004 in 775 US $47.9 \%$. patients rardomized 30 day mort. o. the anced ptomsignificantly raceocculusion infarct-related artery during $\quad$ compared with $\quad 3$ patients $(8 \%$ versus $21 \%, 5)$. in addition, there was a snificantly lower event rate tients assigned to aortic counterpulsation in terms of a co ite clinical en teath, stroke, reinfarction, need for ency revascu ation with angioplasty or bypass surger recurrent mia: $13 \%$ versus $24 \%, \mathrm{p}<.04)$. in a prospd nal study of 293, 633 patients from National ro nyocardial infarction, Jan 1995 - may 775 US hospitals: cardiogenic shock was present in $\Rightarrow$ of patients. There was increase in PPCI rate 54.5\%. The in-hospital mortality in 1995 was $\%$ which was reduced in 2004 to $47.9 \%$.

The in-hospital mortality of AMI complicated by arcinogenic shock in this study is high (50\%). However, this lower compared to historical thrombolytic therapy in AMI with cardiogenic shock. Our present study shows that invasive strategy can be alternative mode of treatment compared to thrombolytic therapy despite high mortality even in developing country like Nepal in highly selected patients.

\section{STUDY LIMITATION}

This is the only national heart centre in Nepal to start PCI service, hence in th initial phase the total number of routine PCI and primary PCI in cardiogenic shock is small. As this is a retrospective study of a single centre with small number of highly selective patients there is no direct control group with thrombolytic therapy. However, the number of patients admitted with AMI in hospital is small in number and among those only very small number of patientscomplicated by cardiogenic shock are admitted in hospital.

\section{CONCLUSION}

In-hospital mortality in patients with acute myocardial infarction complicated by cardiogenic shock remains high, even with early interventional therapy. Every effort should be made to reduce the incidence of cardiogenic shock. Primary PCI in AMI complicated by cardiogenic shock has lower mortality and improved outcome. High cost, high in-hospitalmortality, need for trained manpower are the major limitations. 


\section{REFERENCES}

1. Hasdai D, TOpol EJ, Califf RM, Berger PB, Homes DR Jr. Cardiogenic shock complicating acute coronary syndromes. Lancet. 2000;356:749-756.

2. Goldberg RJ, Samad NA, Yarzebski J et al. Temporal trends in cardiogenic shock complicating acute myocardial infarction. N Engl J Med. 1993;340:11621168.

3. Hasdai D, Holmes DR Jr, Topol EJ, et al. Frequency and clinical outcome of cardiogenic shock during acute myocardial infarction among patients receiving reteplase or alteplase. Results from GUSTO-III Conclusion. EUR Heart J. 1999;20:128-135.

4. Sanborn TA, Sleeper LA, Bates ER, et al. Impact of thrombolysis, intra-aortic balloon pump counterpulsation, and their combination in cardiogenic shock complicating acute myocardial infarction: a report from the SHOCK trial registry. J Am Coll Cardiol. 2000;36:1123-1129.

5. Silver S, Albertsson P, Aviles FF, et al. Guideline for percutaneous coronary intervention. The task Force for Percutaneous Coronary Intervention of the European Society of Cardiology. Eur Heart J. 2005;26:804-847.

6. Smith SC Jr. Feldman TE, Hirshfeld JW Jr. et al. ACC/ AHA/SCAI 2005 Guideline Update for Percutaneious Corornary Intervention-Summary Article. A Report of the American College of Cardiology/American Heart Association Task Force on Practice Guidelines (ACC/ AHA/SCAI Writing Committee to Update the 2001 Guidelines for Percutaneous Coronary Intery ${ }^{m}$ tion). Circulation. 2006;113:156-175.

7. Keely EC, Boura JA, Grines CL. Primary an versus intravenous thrombolytic therapy fo myocardial infarction, a quantitative review randomized trials. Lancet 2003,361:12-20

8. Zijstra F, Hoorntje JC, de Bo benefit of primary angiop thrombolytic therapy for Engl J Med. 1999,341:14
9. Nunn CM, O'Neill WW, Rothbam D, et al. Long term outcome after primary angioplasty: report from primary angioplasty in myocardial infarction (PAMI-I) trial. J Am Coll Cardiol. 1999,33:640-646.

10. Grines CL, Serruys P, O'Neill WW. Fibrinolytic therapy: is it a treatment or past ? Circulation 2003. 2542.

11. Hochman JS, MD, Sleeper LA, White H survival following early revascularizatio shock. JAMA. 2001;285:190-192.

12. Zeymer U, Vogt A, Zahn R, et al. mortality in 1333 Patients with complicated by cardiogeni percutaneous coronary the primary PCI regis Leitende Kardiolo Heart J 2004;5:

13. Chodek A, Prognosti acute $\mathrm{m}$ dial coronary nterventi

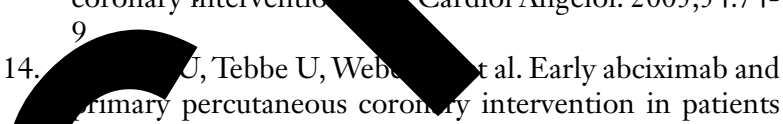
rimary percutaneous coronvy intervention in patients with ST-elevation myocardial infarction complicated by cardiogenic s Results of the REO-SHOCK trial. J nvaive Cardid 03;15:385-9.

15 man EM. rge BS, White CJ, et al Use of aortic to improve sustained coronary artery par ng acute myocardial infarction. Results of a randomized trial. The Randomized IABP Study Group. malation. 1994;90:792-9. ev A, Frederick PD, Pasta DJ, Every N, Sichrovsky T, Hochman JS; NRMI Investigators. Trends in management and outcomes of patients with acute myocardial infarction complicated by cardiogenic shock. JAMA. 2005;294:448-54. 